\title{
Myocardial iron overload in sickle/thalassemia patients of Italian origin
}

\author{
Antonella Meloni ${ }^{1 *}$, Giovan Battista Ruffo ${ }^{2}$, Petra Keilberg ${ }^{1}$, Domenico D’Ascola ${ }^{3}$, Alessandra Quota ${ }^{4}$, \\ Claudio Ascioti ${ }^{5}$, Vincenzo Positano ${ }^{1}$, Cristina Salvatori ${ }^{6}$, Letizia Gulino ${ }^{1}$, Massimo Lombardi ${ }^{1}$, Alessia Pepe \\ From 16th Annual SCMR Scientific Sessions \\ San Francisco, CA, USA. 31 January - 3 February 2013
}

\section{Background}

Sickle-thalassemia is an inherited hemoglobin disorder resulting from the combined heterozygosity for sicklecell and $\beta$-thalassemia genes. Myocardial iron overload in patients with sickle-thalassemia has been poorly studied; however, a report has shown no evidence of cardiac iron in a small group $(\mathrm{n}=10)$ of multitransfused Arab patients. The current study aims to further evaluate cardiac iron overload in a larger group of Italian patients using a $\mathrm{T}^{*}$ multislice approach and explore its correlation with transfusions, age and sex.

\section{Methods}

Fifty-nine sickle-thalassemia patients (29 males, mean age 35.6 \pm 14.1 years), enrolled in the MIOT (Myocardial Iron Overload in Thalassemia) network were considered. Three parallel short-axis views of the left ventricle were acquired and analyzed with a dedicated software (HIPPO MIOT) providing the T2* value on each of 16 segments as well as the global T2* value averaged over all segmental $\mathrm{T}_{2}^{*}$ values and the $\mathrm{T} 2 *$ value in the midventricular segment averaged over the mid-anterior and the mid-inferior septum.

\section{Results}

We found 55 (93\%) patients with all 16 segmental T2* values normal ( $>20 \mathrm{~ms}$ ). Of the 4 patients with abnormal segmental T2* values, all showed an heterogeneous $\mathrm{MIO}$ (some segments with $\mathrm{T} 2 *$ values $>20 \mathrm{~ms}$ and other segments with $\mathrm{T}_{2}^{*}$ values $<20 \mathrm{~ms}$ ) and none showed an homogeneous MIO (all segment with T2* values $<20 \mathrm{~ms}$ ). Out of the 4 patients with heterogeneous MIO, only one had a global T2* global $<20 \mathrm{~ms}$.
The mean global heart $\mathrm{T} 2 *$ value was $34.4 \pm 6.2 \mathrm{~ms}$.

We did not find significant differences among sicklethalassemia regularly $(\mathrm{N}=20)$, sporadically $(\mathrm{N}=32)$ and no transfused $(\mathrm{N}=7)$ in the $\mathrm{T} 2 \%$ global value $(33.4 \pm 7.3$ $\mathrm{ms}$ versus $35.5 \pm 5.4 \mathrm{~ms}$ versus $32.4 \pm 6.3 \mathrm{~ms} ; \mathrm{P}=0.425)$.

On linear regression analysis, there was a statistically significant positive correlation between global T2* and age but with poor linearity $(\mathrm{R}=0.368 ; \mathrm{P}=0.004)$.

The global T2* value was not significant different between males and females $(35.6 \pm 4.9 \mathrm{~ms}$ versus $35.2 \pm 7.2 \mathrm{~ms} ; \mathrm{P}=0.118$ ).

\section{Conclusions}

In respect of myocardial iron deposition, the sickle/ thalassemia patients are similar to patients with homozygous SCD for which iron overloading is relatively rare.

\section{Funding}

The MIOT project receives "no-profit support" from industrial sponsorships (Chiesi and Apotex). This study was also supported by: "Ministero della Salute, fondi ex art. 12 D.Lgs. 502/92 e s.m.i., ricerca sanitaria finalizzata anno 2006" e "Fondazione L. Giambrone".

\section{Author details}

${ }^{1}$ CMR Unit, Fondazione G.Monasterio CNR-Regione Toscana and Institute of Clinical Physiology, Pisa, Italy. ${ }^{2}$ ARNAS Ospedale Civico, Palermo, Italy. ${ }^{3}$ U.O. Microcitemie, A.O. "Bianchi-Melacrino-Morelli", Reggio Calabria, Italy. ${ }^{4}$ Serv. Talassemia, Osp. "V. Emanuele III", Gela, Italy. ${ }^{5}$ Struttura Complessa di Cardioradiologia, P.O. "Giovanni Paolo II", Lamezia Terme, Italy. ${ }^{6}$ Fondazione G.Monasterio CNR-Regione Toscana, Pisa, Italy.

Published: 30 January 2013 
doi:10.1186/1532-429X-15-S1-E106

Cite this article as: Meloni et al: Myocardial iron overload in sickle/

thalassemia patients of Italian origin. Journal of Cardiovascular Magnetic

Resonance 2013 15(Suppl 1):E106.

Submit your next manuscript to BioMed Central and take full advantage of:

- Convenient online submission

- Thorough peer review

- No space constraints or color figure charges

- Immediate publication on acceptance

- Inclusion in PubMed, CAS, Scopus and Google Scholar

- Research which is freely available for redistribution

Submit your manuscript at 